\title{
The effect of viewing fitness imagery on body dissatisfaction: sex and physical activity differences
}

\section{Conor J. Rothwell \& Deirdre Desmond}

To cite this article: Conor J. Rothwell \& Deirdre Desmond (2018) The effect of viewing fitness imagery on body dissatisfaction: sex and physical activity differences, Psychology, Health \& Medicine, 23:8, 980-986, DOI: 10.1080/13548506.2018.1442009

To link to this article: https://doi.org/10.1080/13548506.2018.1442009

曲 Published online: 22 Feb 2018.

6 Submit your article to this journal

Џll Article views: 291

Q View related articles $\sqsubset$

View Crossmark data \lceil 


\title{
The effect of viewing fitness imagery on body dissatisfaction: sex and physical activity differences
}

\author{
Conor J. Rothwell (D) and Deirdre Desmond \\ Department of Psychology, Maynooth University, Co. Kildare, Ireland
}

\begin{abstract}
Exposure to cultural bodily ideals featuring thinness and muscularity can have deleterious effects on body satisfaction. The current study explores the effect of exposure to such imagery on body dissatisfaction and the influence of internalisation of cultural and athletic ideals. 188 (97 male) adults (18-25yrs; $M=20.97$ ) were grouped according to a $2 \times 2 \times 2$ mixed between-within subjects design (male/female; high/low physical activity; intervention/control). Participants were exposed to images of idealised physiques or neutral images. Internalisation-general, sex, physical activity levels, and Body Mass Index were associated with baseline levels of body dissatisfaction. Internalisation of cultural ideals appears to be an important factor for the prediction of body dissatisfaction. Exposure to idealised images resulted in increases in body dissatisfaction across all groups compared to controls. Neither sex nor physical activity levels buffer young adults from the negative effects of viewing images featuring idealised bodies.
\end{abstract}

\section{ARTICLE HISTORY}

Received 19 April 2017

Accepted 9 February 2018

\section{KEYWORDS}

Body dissatisfaction; idealised images; internalisation; fitness images

\section{Introduction}

Social media is a major conveyor of idealised body images. Female bodily ideals incorporate toned muscularity and thinness (Varnes et al., 2013; Willis \& Knobloch-Westerwick, 2014). Male ideals are characterised by muscularity, leanness, and height (Galioto \& Crowther, 2013). These ideals are pervasive on social media platforms; im ${ }^{\mathrm{Tm}}$ ages with tags emphasizing thinness and muscularity, e.g. \#fitspiration, are increasingly popular (Boepple \& Thompson, 2016). Experimental research, predominantly using adolescent or young adult female samples, links exposure to idealised images with increased body dissatisfaction (Hargreaves \& Tiggemann, 2003; Tiggemann \& Slater, 2004). While less is known about the impact of such exposures on males, the effects appear to be similar (Blond, 2008).

Internalisation, endorsement of socially constructed ideals (Homan, McHugh, Wells, Watson, \& King, 2012), offers a potential link between imagery exposure and body dissatisfaction. Among adolescent females, high internalisers report greater body dissatisfaction (Shroff \& Thompson, 2006), and are more likely to act to change the body to approximate cultural ideals (Thompson \& Stice, 2001). 
Exercise can buffer against body image concerns (Robinson \& Ferraro, 2004). Athletes report fewer body image concerns (Varnes et al., 2013); female athletes generally report higher body-related self-esteem (Armstrong \& Oomen-Early, 2009), and less body dissatisfaction (Robinson \& Ferraro, 2004) than non-athletes. However, the benefits are not universal; participants (particularly females) in sports emphasising lean body types, report greater dissatisfaction and more health damaging behaviours than non-athletes (Van Durme, Goossens, \& Braet, 2012). Many studies investigate body dissatisfaction in collegiate athletes. Findings may not be generalizable as collegiate athlete status is more complex than increased physical activity (Varnes et al., 2013). Studies comparing body dissatisfaction among children of varying activity levels demonstrate protective effects (Gaspar, Amaral, Oliveira, \& Borges, 2011). These effects are evident for older women and males (Tiggemann \& Williamson, 2000), but are less clear among adolescent and young adult women, as many exercise for appearance rather than health reasons; this type of exercise is associated with negative body image (Slater \& Tiggemann, 2006). Few studies have examined whether exercise buffers against exposure to idealised images and studies examining protective effects of exercise on body dissatisfaction are typically based on pre-adolescent or adolescent samples (Blanchette-Sylvestre \& Meilleur, 2016; Gaspar et al., 2011). This study explores intergroup differences in body image dissatisfaction after exposure to idealised images across sexes and activity levels in young adults.

\section{Materials and methods}

\section{Design and procedure}

This experiment was conducted online and employed a $2 \times 2 \times 2$ mixed between-within-subjects design. Participants responded to a link describing the study and were quasi-randomly assigned to view same-sex fitness imagery or neutral (control) images according to sex (male/female) and activity levels (inactive-moderately active/highly active). Groups were well matched (control group $=96$, experimental group $=92$; males $=97$, females $=91$; highly-active $=75$, inactive/moderately-active $=113$ ). Demographics, level of activity, internalisation and body dissatisfaction were collected prior to image exposure. Body dissatisfaction was measured again post-exposure.

\section{Experimental manipulation: image type}

Two sets of 25 sex-specific images, featuring muscular/thin-muscular individuals, were compiled. Six males and six females rated the representativeness of 70 candidate images independently; the 25 highest rated images formed experimental sets. The control condition incorporated 25 neutral (travel) images. Images were presented for $4 \mathrm{~s}$ each.

\section{Measures}

\section{Body dissatisfaction}

'Weight dissatisfaction' and 'appearance dissatisfaction' were measured using two questions developed by Tiggemann and Zaccardo (2015). Participants reported 'how much of the 
following you feel right now' on 10-point Likert scales. A body dissatisfaction score was derived by summing the responses (range $=2-20$ ); internal consistency was acceptable $(\alpha=.84)$.

\section{Physical activity and BMI}

Participants reported the number of 'minutes spent on vigorous-intensity aerobic physical activity per week'. Based on World Health Organisation (WHO) recommendations, $150 \mathrm{~min}$ of vigorous activity was classified 'highly active'; less than $150 \mathrm{~min}$ was classified 'inactive/moderately' active (WHO, 2016). BMI was calculated as weight (kg) divided by height squared $(\mathrm{m})$.

\section{Internalisation}

The Internalization-General (I-G) and Internalisation-Athletic (I-A) subscales of the Sociocultural Attitudes Toward Appearance Questionnaire (Thompson, van den Berg, Roehrig, Guarda, \& Heinberg, 2004) measured endorsement and striving toward prevailing standards of attractiveness ( 9 items) and the desirability of a toned, athletic appearance (5 items), respectively. Total subscale scores are calculated by summing responses; higher scores indicate greater endorsement. Internal reliability was acceptable $\left(\alpha_{\mathrm{I}-\mathrm{G}}=.879\right.$; $\left.\alpha_{\mathrm{I}-\mathrm{A}}=.769\right)$

\section{Statistical analysis}

Data were analysed using IBM SPSS 21.0. Hierarchical regression was used to investigate associations between predictor variables and baseline body dissatisfaction. The effect of idealised image exposure was investigated using mixed between-within ANOVAs, with time (pre- and post-exposure) as the between groups factor, and experimental group, sex, and activity level as within group factors.

\section{Results}

\section{Sample characteristics}

Participants aged between 18 and 25 years $(M=20.97, \mathrm{SD}=1.25)$. Table 1 includes descriptive statistics for the baseline measures. There were no significant group differences at baseline (all p's > .05).

\section{Effect of experimental condition, sex, and physical activity on body dissatisfaction}

Table 2 displays means and standard deviations for body dissatisfaction according to experimental condition (control/fitness), sex, and activity group.

There was a significant interaction between time and experimental group, Wilks Lambda $=.996, F(1,183)=6.42, p=.012$, partial eta squared $=.034$ (small effect) in ANOVA investigating the impact of image exposure on body dissatisfaction across sex, across time. Participants exposed to idealised images had significantly higher body dissatisfaction 
Table 1. Means and standard deviations for baseline measures.

\begin{tabular}{|c|c|c|c|c|c|}
\hline & \multicolumn{5}{|c|}{ Experimental condition } \\
\hline & Total $(n=188)$ & Fitness $(n=92)$ & Control $(n=96)$ & & \\
\hline & Mean (SD) & Mean (SD) & Mean (SD) & $p$ value & $t / \chi^{2}$ \\
\hline Age & $20.97(1.25)$ & $20.91(1.32)$ & $21.02(1.22)$ & .557 & .588 \\
\hline Gender (Male) & $51.6 \%$ & $51.1 \%$ & $52.1 \%$ & & \\
\hline \multicolumn{6}{|l|}{ Athletic rating } \\
\hline Low/Moderately active & $60.1 \%$ & $58.7 \%$ & $61.5 \%$ & .812 & .057 \\
\hline Highly active & $39.9 \%$ & $41.3 \%$ & $38.5 \%$ & & \\
\hline Body Mass Index & $22.92(3.16)$ & $22.94(2.96)$ & $22.91(3.35)$ & .943 & -.072 \\
\hline Normal range (18.5-24.99) & $75 \%$ & $75 \%$ & $75 \%$ & & \\
\hline Internalisation - General & $27.69(7.76)$ & $28.18(7.96)$ & $27.24(7.58)$ & .414 & -.819 \\
\hline Internalisation - Athlete & $17.89(4.02)$ & $18.08(4.00)$ & $17.70(4.07)$ & .528 & -.633 \\
\hline Pre-exposure body Dissatisfaction & $9.58(4.68)$ & $9.60(4.59)$ & $9.56(4.80)$ & .959 & -.052 \\
\hline
\end{tabular}

Note: Italicised values are the standard deviations of the corresponding mean values.

Table 2. Pre- and post-exposure means and standard deviations for body dissatisfaction as a function of experimental condition, gender, and athletic grouping.

\begin{tabular}{lllrrrr}
\hline & \multicolumn{5}{c}{ Body dissatisfaction } \\
\cline { 2 - 6 } & & Condition & Pre exposure & (SD) & Post exposure & $($ SD) \\
\hline Group totals & Fitness & & 9.60 & $(4.59)$ & 10.15 & $(5.26)$ \\
& Control & & 9.56 & $(4.80)$ & 9.31 & $(4.62)$ \\
Sex group comparison & Fitness & Female & 10.64 & $(4.92)$ & 11.58 & $(5.70)$ \\
& & Male & 8.60 & $(4.04)$ & 8.79 & $(4.44)$ \\
& \multirow{3}{*}{ Control } & Female & 11.54 & $(4.71)$ & 11.07 & $(4.34)$ \\
Physical activity group & & Male & 7.74 & $(4.15)$ & 7.72 & $(4.32)$ \\
comparison & \multirow{2}{*}{ Fitness } & Highly active & 8.55 & $(3.60)$ & 8.71 & $(4.46)$ \\
& & Low/mod active & 10.33 & $(5.07)$ & 11.17 & $(5.57)$ \\
& \multirow{2}{*}{ Control } & Highly active & 7.86 & $(4.50)$ & 7.92 & $(4.76)$ \\
& & Low/mod active & 10.63 & $(4.70)$ & 10.19 & $(4.35)$ \\
\hline
\end{tabular}

Note: Italicised values are the standard deviations of the corresponding mean values.

post-exposure compared to the control group. Body dissatisfaction changes were not associated with sex.

A mixed between within ANOVA assessed the impact of exposure to idealised imagery on body dissatisfaction compared to control images across activity group and time. There was a significant interaction effect between time and experimental group, Wilks Lambda $=.977$, $F(1,183)=4.30, p=.039$, partial eta squared $=.023$ (small effect). Participants exposed to idealised images had significantly higher body dissatisfaction. Changes in body dissatisfaction were not associated with physical activity levels.

\section{Predictors of body dissatisfaction}

Age, sex, BMI and activity level were entered at step one, explaining $18.5 \%$ of the variance in baseline body dissatisfaction. I-G and I-A were entered at step two, the variance explained by the model was $31.5 \%, F(6,176)=13.50, p<.001$ (Table 3 ). The internalisation measures explained $13 \%$ of the variance in body dissatisfaction, $R^{2}$ change $=.13, F$ change $(2,176)=$ $16.73, p<.001$. In the final model, I-G $(\beta=.304, p<.001)$, sex $(\beta=-.269, p<.001)$, activity level $(\beta=-.193, p=.004)$, and BMI $(\beta=.193, p=.004)$ made statistically significant unique contributions. Body dissatisfaction was associated with greater internalisation, being female, higher BMI, and being in the low-moderate activity group. 
Table 3. Multiple regression with baseline body dissatisfaction as the dependent variable.

\begin{tabular}{|c|c|c|c|c|}
\hline \multirow[b]{2}{*}{ Model } & \multicolumn{4}{|c|}{ Baseline body dissatisfaction } \\
\hline & $R^{2}$ & Change in $R^{2}$ & Standardised $\beta$ & $p$ value \\
\hline 1 & .185 & & & \\
\hline Age & & & -.117 & .098 \\
\hline Sex & & & -.333 & $<.001$ \\
\hline Physical activity level & & & -.205 & .004 \\
\hline Body Mass Index & & & .218 & .002 \\
\hline 2 & .315 & .130 & & \\
\hline Age & & & -.108 & .097 \\
\hline Sex $($ Male $=1)$ & & & -.269 & $<.001$ \\
\hline Physical activity level & & & -.193 & .004 \\
\hline Body Mass Index & & & .193 & .004 \\
\hline Internalisation - General & & & .304 & $<.001$ \\
\hline Internalisation - Athletic & & & 127 & .072 \\
\hline
\end{tabular}

*Figures in bold indicate a significant unique contribution.

\section{Discussion}

This study explored differences in body image dissatisfaction following exposure to idealised body images across sexes and activity levels in young adults, and explored predictors of baseline body dissatisfaction. Higher internalisation (I-G) and BMI, being female, and lower activity levels were associated with greater baseline body dissatisfaction. Compared to controls, participants exposed to idealised images reported significantly higher levels of body dissatisfaction post-exposure. Neither sex, nor activity levels buffered the negative effects of viewing idealised images. The association between sex and body dissatisfaction is consistent with literature emphasizing unhappiness with body shape/appearance among females (Knauss, Paxton, \& Alsaker, 2007). However, the current findings highlight the equity of vulnerability across sexes when exposed to idealised images. Others have documented buffering effects of sex on vulnerability to body image disturbances, with males reporting less induced dissatisfaction (e.g. Hargreaves \& Tiggeman, 2004). In 2004, Hargreaves and Tiggeman proposed that as depictions of male ideals become more pervasive, males might become increasingly vulnerable to media induced body image disturbances. Recent evidence (e.g. Blond, 2008; Buote, Wilson, Strahan, Gazzola, \& Papps, 2011) including the current findings, supports this suggestion.

Inconsistencies in terms of a protective or risk enhancing impact of athletic participation on body image disturbance are likely due to sample differences with elite athletes reporting higher dissatisfaction compared to both non-elite groups and controls (Smolak, Murnen, \& Ruble, 2000). Pressures and expectations associated with elite sport may underpin this effect. Non-elite athletes might gain the benefits of exercise without the negative impacts of elite status. The association between physical activity and lower body dissatisfaction in this non-elite athlete sample is consistent with this proposal and findings elsewhere (Varnes et al., 2013). The lack of effect for exercise is surprising given the baseline differences between groups. Despite being closer to the cultural ideal, discrepancies between the ideal and actual bodies of those in the higher physical activity group might persist and highlighting this discrepancy potentially increases body dissatisfaction.

The findings must be interpreted in the context of limitations. The design made it difficult to blind participants to the nature of the study; there is an inevitable possibility of socially desireable responding. Retrospective reports of physical activity may also be problematic. 


\section{Conclusions}

There is nothing intrinsic about being female or less active that makes an individual more vulnerable to body dissatisfaction following exposure to idealised body images. These groups do, however, experience significantly higher levels of body dissatisfaction. A possible explanation for the apparent contradiction in the sex-difference findings is that exposure to idealised imagery is more pervasive among females (Buote et al., 2011). Differential exposure is unlikely to explain the findings related to physical activity and more research is required to explore why the relationship between body dissatisfaciton and physical activity was not maintained throughout the study.

\section{Disclosure statement}

No potential conflict of interest was reported by the authors.

\section{Funding}

This research did not receive any specific grant from funding agencies in the public, commercial, or not-for-profit sectors.

\section{ORCID}

Conor J. Rothwell (D) http://orcid.org/0000-0003-2631-5193

\section{References}

Armstrong, S., \& Oomen-Early, J. (2009). Social connectedness, self-esteem, and depression symptomatology among collegiate athletes versus nonathletes. Journal of American College Health, 57(5), 521-526.

Blanchette-Sylvestre, M., \& Meilleur, D. (2016). Activité physique et insatisfaction de l'image corporelle chez un groupe d'adolescentes [Physical activity and body image dissatisfaction among a group of teenage girls]. Revue canadienne des sciences du comportement [Canadian Journal of Behavioural Science], 48(3), 204-216.

Blond, A. (2008). Impacts of exposure to images of ideal bodies on male body dissatisfaction: A review. Body Image, 5(3), 244-250.

Boepple, L., \& Thompson, J. K. (2016). A content analytic comparison of fitspiration and thinspiration websites. International Journal of Eating Disorders, 49(1), 98-101.

Buote, V. M., Wilson, A. E., Strahan, E. J., Gazzola, S. B., \& Papps, F. (2011). Setting the bar: Divergent sociocultural norms for women's and men's ideal appearance in real-world contexts. Body Image, $8(4), 322-334$.

Galioto, R., \& Crowther, J. H. (2013). The effects of exposure to slender and muscular images on male body dissatisfaction. Body Image, 10(4), 566-573.

Hargreaves, D., \& Tiggemann, M. (2003). The effect of 'thin ideal' television commercials on body dissatisfaction and schema activation during early adolescence. Journal of Youth and Adolescence, 32(5), 367-373.

Hargreaves, D. A., \& Tiggeman, M. (2004). Idealized media images and adolescent body image: 'Comparing' boys and girls. Body Image, 1(4), 351-361.

Homan, K., McHugh, E., Wells, D., Watson, C., \& King, C. (2012). The effect of viewing ultra-fit images on college women's body dissatisfaction. Body Image, 9(1), 50-56. 
Knauss, C., Paxton, S. J., \& Alsaker, F. D. (2007). Relationships amongst body dissatisfaction, internalisation of the media body ideal and perceived pressure from media in adolescent girls and boys. Body Image, 4(4), 353-360.

Gaspar, M. J., Amaral, T. F., Oliveira, B. M., \& Borges, N. (2011). Protective effect of physical activity on dissatisfaction with body image in children-A cross-sectional study. Psychology of Sport and Exercise, 12(5), 563-569.

Robinson, K., \& Ferraro, F. R. (2004). The relationship between types of female athletic participation and female body type. The Journal of Psychology, 138(2), 115-128.

Shroff, H., \& Thompson, J. K. (2006). The tripartite influence model of body image and eating disturbance: A replication with adolescent girls. Body Image, 3, 17-23.

Slater, A., \& Tiggemann, M. (2006). The contribution of physical activity and media use during childhood and adolescence to adult women's body image. Journal of Health Psychology, 11(4), 553-565.

Smolak, L., Murnen, S. K., \& Ruble, A. E. (2000). Female athletes and eating problems: A metaanalysis. International Journal of Eating Disorders, 27(4), 371-380.

Thompson, J. K., \& Stice, E. (2001). Thin-ideal internalization: Mounting evidence for a new risk factor for body-image disturbance and eating pathology. Current Directions in Psychological Science, 10(5), 181-183.

Thompson, J. K., van den Berg, P., Roehrig, M., Guarda, A. S., \& Heinberg, L. J. (2004). The sociocultural attitudes towards appearance scale-3 (SATAQ-3): Development and validation. International Journal of Eating Disorders, 35(3), 293-304.

Tiggemann, M., \& Slater, A. (2004). Thin ideals in music television: A source of social comparison and body dissatisfaction. International Journal of Eating Disorders, 35(1), 48-58.

Tiggemann, M., \& Williamson, S. (2000). The effect of exercise on body satisfaction and self-esteem as a function of gender and age. Sex Roles, 43, 119-127.

Tiggemann, M., \& Zaccardo, M. (2015). Exercise to be fit, not skinny: The effect of fitspiration imagery on women's body image. Body Image, 15, 61-67.

Van Durme, K., Goossens, L., \& Braet, C. (2012). Adolescent aesthetic athletes: A group at risk for eating pathology? Eating Behaviors, 13(2), 119-122.

Varnes, J. R., Stellefson, M. L., Janelle, C. M., Dorman, S. M., Dodd, V., \& Miller, M. D. (2013). A systematic review of studies comparing body image concerns among female college athletes and non-athletes, 1997-2012. Body Image, 10(4), 421-432.

World Health Organisation. (2016). Global strategy on diet, physical activity and health. Geneva: Author. Retrieved from http://www.who.int/dietphysicalactivity/factsheet_adults/en/

Willis, L. E., \& Knobloch-Westerwick, S. (2014). Weighing women down: Messages on weight loss and body shaping in editorial content in popular women's health and fitness magazines. Health Communication, 29(4), 323-331. 